\title{
Beyond Insecurity: A Reconceptualization of Attachment Disorders of Infancy
}

\author{
Charles H. Zeanah \\ Louisiana State University
}

\begin{abstract}
Some young children are not merely insecurely attached and at risk for later problems; by virtue of the severity of their attachment disturbances they are already disordered. This article reviews and critiques the approaches of the Diagnostic and Statistical Manual of Mental Disorders (4th ed.; DSM-IV; American Psychiatric Association, 1994) and the International Classification of Diseases (10th ed.; ICD-10; World Health Organization, 1992) to attachment disorders and finds that they have not made use of findings from developmental research on attachment in developing their criteria. An alternative system of classifying attachment disorders that is compatible with the major findings from developmental research on infant-caregiver attachment is presented. Finally, many areas in need of empirical contributions are indicated.
\end{abstract}

Ethological attachment theory, as outlined by John Bowlby (Bowlby, 1969, 1973, 1980), has provided one of the most important frameworks for understanding crucial risk and protective factors in social and emotional development in the first 3 years of life. Bowlby's (1951) monograph, Maternal Care and Mental Health, reviewed the world literature on maternal deprivation and suggested that emotionally available caregiving was crucial for infant development and mental health.

Developmental attachment research, which has formally evaluated Bowlby's major premises, has demonstrated convincingly that insecure attachment in infancy is associated with subsequent psychosocial maladaptation in preschool and middle childhood years (Cassidy, 1988; Lewis, Feiring, McGuffog, \& Jaskir, 1984; Easterbrooks \& Goldberg, 1990; Erickson, Sroufe, \& Egeland, 1985; Sroufe, 1983; Troy \& Sroufe, 1987; Wartner, Grossmann, Fremmer-Bombik, \& Suess, 1994). Infants who are insecurely attached at 1 year of age to their mothers demonstrate more interactive disturbances with their mothers at home and in the laboratory (Matas, Arend, \& Sroufe, 1978; Solomon, George, \& Ivins, 1989; Waters, Wippman, \& Sroufe, 1979), less social competence with peers (Arend, Gove, \& Sroufe, 1979; Troy \& Sroufe, 1987), and more problematic relationship with their teachers (Sroufe, 1983). Links between insecure attachment classifications in infancy and subsequent behavior problems have been mixed when parents rate behavior problems (Bates, Maslin, \& Frankel, 1985; Fagot \& Kavanaugh, 1990; Lewis et al., 1984) but have been more consistent when teachers or observers rate behavior problems (Erickson et al., 1985; Fagot \& Kavanaugh, 1990; Suess, Grossman, \& Sroufe, 1992; Wartner, Grossman, Fremmer-Bombik, \& Suess, 1994). Inves-

An earlier version of this article was presented in November 17-18, 1992, at the National Institute of Mental Health Workshop "Attachment and Psychopathology," Washington, DC.

Correspondence concerning this article should be addressed to Charles H. Zeanah, Department of Psychiatry, Louisiana State University School of Medicine, 1542 Tulane Avenue, New Orleans, Louisiana $70112-2822$ tigations in high-risk samples have suggested strong associations between disorganized attachment classifications and preschool behavior problems (Hubbs-Tait et al., 1991; Lyons-Ruth, Rapacholi, McLeod, \& Silva, 1991).

Overall, studies of attachment have supported the central theses of Bowlby's framework. Nevertheless, developmental attachment research is grounded in a risk and protective factors approach that typifies developmental psychopathology. As such, it has focused on demonstrating probabilistic relationships between attachment classifications in infancy and subsequent indices of psychological adaptation (Sroufe, 1988).

Bowlby's work has also been important in the clinical tradition of attachment disorders. This tradition, typified by descriptions of attachment disorders in the Diagnostic and Statistical Manual of Mental Disorders (4th ed,; DSM-IV; American Psychiatric Association, 1994) and the International Classification of Diseases (10th ed.; ICD-10; World Health Organization, 1992), has focused on young children who are not merely at increased risk for subsequent disorders but who are disordered already. Clinically disordered attachment represents an extreme and impaired subgroup of children with insecure attachments. Thus, disordered attachments are all insecure attachments, but most insecure attachments are not disordered. Clinically disordered attachments are the major focus of this article.

Reactive attachment disorder is one of the few diagnostic categories applicable to children under 3 years of age in standard nosologies of psychological disorders. Despite its potential importance, there are no published studies about its validity. In fact, attachment disorders are mentioned hardly at all in literature published since it first appeared in the Diagnostic and Statistical Manual of Mental Disorders (3rd ed.; DSM-III; American Psychiatric Association, 1980) 15 years ago. During this same period of time, there has been an unprecedented explosion of knowledge from developmental research on attachment that has not been included in criteria for diagnostic categories of attachment disorders. One purpose of this article is to review and critique the $D S M-I V$ and ICD-10 criteria for attachment disorders and to suggest that they would benefit from more sub- 
stantively integrating the knowledge base available from developmental research on attachment.

After briefly reviewing the historical perspective on clinical attachment disorders, I consider the criteria for attachment disorders in the $D S M-I V$ and ICD-10, and I highlight their similarities and differences. A detailed critique of these criteria follows, primarily from the standpoint of what is known about attachment from developmental research. The central thesis of this article is that if attachment disorders are defined by criteria derived from findings in attachment research, they become applicable to a broader range of children in severely disturbed relationships with their primary caregivers, rather than only to some children who have been physically abused or extremely deprived. In conclusion, an alternative system of classification that attempts to integrate findings from developmental research into criteria for attachment disorders is outlined briefly, and some directions for research are highlighted.

\section{Historical Perspective on Attachment Disorders}

Clinicians have been concerned at least since the beginning of the 20th century with the psychological development and wellbeing of children raised in institutions (Chapin, 1915). Still, for the first half of the century, most objections to institutional care for infants went unheeded. Skeel's (1966) observations of improvement and cognitive delays and social functioning of institutionalized infants were dismissed by the scientific community until 25 years after he originally made them because he implied that environment might have profound effects on intelligence. Similarly, many other demonstrations of the abysmal psychological status of children in institutions had little impact, perhaps because the children's status was thought to be the cause of rather than the result of institutional rearing. Some have argued that it was actually the movies of Rene Spitz about infants in institutions that awakened the consciences of thousands of viewers and called attention to the problem in a way that publications in professional journals during the preceding 50 years had not.

Large numbers of European children who had been separated from their parents or actually orphaned by World War II led the World Health Organization to commission a British child psychiatrist, John Bowlby, to prepare a report on the mental health needs of homeless children. Maternal Care and Mental Health was published in 1951, and it summarized the observations of Spitz (1945, 1946), Goldfarb (1945), and many other clinicians about the harmful effects of institutionalization. It also contained the foundation of Bowlby's ideas about attachment that evolved into ethological attachment theory, described in his now famous Attachment and Loss trilogy, Attachment (Bowlby, 1969), Separation (Bowlby, 1973), and Loss (Bowlby, 1980).

In the meantime, research findings about children raised in institutions accumulated (Provence \& Lipton, 1962; Tizard \& Hodges, 1978; Tizard \& Rees, 1974, 1975), case reports of children raised in extremely abusive and depriving environments continued to appear (Curtiss, 1977; Koluchova, 1972; Skuse, 1984; Thompson, 1986), and social characteristics of maltreated children were delineated (Aber \& Allen, 1987; Aber \& Cicchetti, 1984; Gaensbauer \& Sands, 1979; George \& Main, 1979; Main \& George, 1985; Mueller \& Silverman, 1989; Powell, Low, \& Speers, 1987).
As for the official nosologies, the Diagnostic and Statistical Manual of Mental Disorders (2nd ed.; DSM-II; American Psychiatric Association, 1968) did not mention attachment disorders, although it illustrated "adjustment reaction of infancy" with the protest response of an infant separated from his or her mother and described it as characterized by "crying spells, loss of appetite, and severe social withdrawal (p. 49)." Attachment disorders also were not described in the ninth edition of the ICD (ICD-9; World Health Organization, 1978). Their first appearance in the official nosologies was in 1980 in the $D S M-I I I$. At that time, reactive attachment disorder was equated with failure to thrive, (Spitzer \& Cantwell, 1980), although with the curious requirement that onset of the disorder occur before 8 months of age. Because selective attachments occur between 6 and 9 months of age, infants were required to develop onset of a disordered attachment often before they even had expressed a preferred attachment. Criteria were substantially revised in the revised third edition of the $D S M$ (DSMIII-R; American Psychiatric Association, 1987), including dropping failure to thrive as a central feature of the disorder and changing age of onset to within the first 5 years of life. In the DSM-III$R$, two clinical types of "inhibited" and "disinhibited" attachment disorders were introduced, types that have persisted in the newer classifications of the $D S M-I V$ and ICD-10. Reliability of diagnosis of reactive attachment disorder improved dramatically with these changes in criteria (Volkmar, in press).

\section{Attachment Disorders and Contemporary Nosologies}

Criteria for attachment disorders as described in the DSM-IV and ICD-10 are presented in Appendixes A and B. As can be seen, they both preserve the distinction, first introduced in the DSM$I I I-R$, between two major clinical types of attachment disorder Zeanah and Emde (1994) have suggested that two major data bases informed these criteria. Characteristics of social behavior in maltreated children, identified in a number of investigations during the past 15 years, are found in descriptions of the withdrawn, unresponsive child who seeks comfort in deviant ways (Gaensbauer \& Sands, 1979; George \& Main, 1979; Main \& George, 1985; Mueller \& Silverman, 1989; Powell et al., 1987). These characteristics are used to describe the inhibited or deviant type of reactive attachment disorder in DSM-IV (see Appendix A) and to describe reactive attachment disorder in the ICD-10 ( Appendix B). Research on the characteristics of children raised in institutions (Provence \& Lipton, 1962; Skeels, 1966; Tizard \& Hodges, 1978; Tizard \& Rees, 1974, 1975) has influenced the criteria for the disinhibited and indiscriminately social type of attachment disorder. In the Tizard and Rees (1975) investigation, for example, 10 of 26 children institutionalized for their first 4 years of life were noted on evaluation at age 4.5 years to have superficial attachments to staff members, with attention-seeking, clinginess, and overfriendly behavior with strangers being notable social characteristics.

\section{Similarities in Criteria for DSM-IV and ICD-10 Attachment Disorders}

A review of the $D S M-I V$ and ICD-10 criteria in Appendixes $A$ and $B$ indicate substantial agreement about the major features of the disorders. In both nosologies, the disorders involve 
a persistent disturbance in the child's social relatedness that begins before age 5 and that extends across social situations. Attachment disorders in both nosologies must be distinguished from pervasive developmental disorders. As noted, both agree that there are two distinct clinical pictures of attachment disorders. One type of disorder is designated as inhibited, wherein ambivalent, inhibited, or hypervigilant responses are centered on one or more adults. The other type is designated as disinhibited, wherein there is indiscriminate oversociability, a failure to show selective attachments, a relative lack of selectivity in the persons from whom comfort is sought, and poorly modulated social interactions with unfamiliar persons across a range of social situations.

Although they give it varying emphasis, criteria in both nosologies tie the disorders etiologically to parental abuse or neglect or to extremes of caregiving such as children raised in institutions. Developers of the $D S M-I V$ decided to maintain a requirement from the $D S M-I I I-R$ (American Psychiatric Association, 1987) that there be evidence of grossly pathogenic caregiving (e.g., frank neglect, harsh treatment) or repeated changes in caregivers (see Appendix A). ICD-10 also does not make explicit the requirement of parental maltreatment, although the syndrome is believed to result from "severe parental neglect, abuse or serious mishandling" (World Health Organization, 1992, p. 279), and the clinician is urged to use caution in making the diagnosis "in the absence of evidence of abuse or neglect" (World Health Organization, 1992, p. 281). Clearly, the link with parental maltreatment strongly influences the criteria of both systems of classification.

\section{Differences in DSM-IV and ICD-10 Disorders of Attachment}

Differences in criteria for attachment disorders in the two nosologies are more subtle. The DSM-IVlumps together two clinical pictures under the single category of reactive attachment disorder, whereas the ICD-10 makes each of the clinical pictures into a distinctive type. In the ICD-10 criteria, the child must have the capacity for social responsiveness as revealed in interactions with nondeviant adults. In contrast, the $D S M-I V$ emphasizes that abnormal social behavior ought to be apparent in most social contexts. Thus, criteria in both systems deemphasize the child's behavior with the attachment figure, although the $D S M-I V$ is most explicit about a lack of relationship variability. Finally, the $D S M-I V$ explicitly excludes children with mental retardation from a diagnosis of reactive attachment disorder if any of the prominent symptoms are believed to be due to cognitive delays (Appendix A). The ICD-10, on the other hand, makes no such exclusion, although the child with reactive attachment disorder must demonstrate elements of normal relatedness when interacting with responsive adults (Appendix B).

\section{Critique of Attachment Disorders in Contemporary Nosologies}

To organize a discussion of usefulness of $D S M-I V$ and ICD10 criteria for attachment disorders, I consider three questions about reactive attachment disorder here: Is it reactive? Is it attachment? Is it a disorder?

\section{Is It Reactive?}

The emphasis in contemporary nosologies on attachment disorders as "reactive" appears to serve two functions: First, it attempts to differentiate them from the pervasive developmental disorders, which also profoundly affect the social behavior of young children; second, it ties them etiologically to maltreatment. Serious questions may be raised about the usefulness of this emphasis.

The ICD-10 suggests that the attachment disorders may be distinguished from pervasive developmental disorders in a number of ways: (a) a normal capacity for social relatedness in reactive attachment disorder, (b) remission of social abnormalities in a normal rearing environment in reactive attachment disorder, (c) distinctive communicative and language abnormalities in pervasive developmental disorders, (d) cognitive deficits that improve with improvements in the caregiving environment only in reactive attachment disorder, and (e) persistently restricted, repetitive, and stereotyped patterns of behavior, interests, and activities are features of pervasive developmental disorders but not attachment disorders (World Health Organization, 1992).

The reason for the effort to distinguish attachment disorders from pervasive developmental disorders is the belief that the social behaviors in the two conditions are similar. The underlying rationale for the distinction is that similar appearing aberrant social behaviors may be the result of different mechanisms of pathogenesis. In the case of attachment disorders, children with intact central nervous systems who experience extremes of maltreatment and deprivation are believed to develop socially unresponsive and deviant behaviors. In the case of pervasive developmental disorders, children are presumed to have central nervous system abnormalities (as yet undelineated) that are responsible for the socially deviant behaviors. Thus, the DSM$I V$ explicitly excludes children with pervasive developmental disorders (Appendix A) and the ICD-10 emphasizes the capacity for normal social interaction in children with attachment disorders (discussed earlier; see Appendix B also).

Essentially, this emphasis represents a version of the functional versus organic dichotomy that characterized thinking about psychiatric disorders in the 1960 s. As we have learned more about brain-behavior relationships, the functional versus organic dichotomy has proven less useful. Our nosologies no longer attempt to distinguish between endogenous and reactive depression, for example, because it is widely recognized that ongoing interactions between life events and brain neurochemistry contribute to the symptoms and to the amelioration of symptoms of affective disorders (Hirshfield \& Goodwyn, 1988). Many psychiatric disorders are reactive in the sense that their clinical picture represents a final common pathway of individual biology and psychology expressed in a social context.

If it were possible to determine the etiology of a given clinical picture of young children who exhibit problems with relatedness with certainty, the distinction might be more valuable. From a practical standpoint, it may not be possible to make an etiologic determination at a given time of assessment. A child exhibiting symptomatic behavior who has a reliable history of adequate caregiving with opportunities for attachment to one or two figures suggests a central nervous system abnormality, 
but such a history is neither always nor even often available in the clinical setting. Not uncommonly, a symptomatic child is referred for evaluation with a clinical picture of aberrant social behavior and a history of foster care of unknown quality (e.g., see Zeanah, Mammen, \& Lieberman, 1993; Richters \& Volkmar, 1994). If the child's symptoms improve significantly with changes in the caregiving context, attachment disorders are likely, but this, of course, cannot be known beforehand. Furthermore, it is not clear how much the clinical picture represents neither a main effect of central nervous system abnormalities alone nor of environmental adversity alone but some ongoing interaction between the two.

A better question for the clinician is whether distinctions can be made between the socially deviant behaviors in pervasive developmental disorders and those in attachment disorders, as asserted in the ICD-10. There are few data available to address this question directly, in part because of the vagueness about the abnormalities in social behavior that have characterized descriptions of attachment disorders. Children raised in institutions are problematic as the sole source of data because it is not always clear what factors led parents to place the children there originally. If parents detected early signs of socially aberrant behavior in their infants, then one of the reasons for placement may have been the abnormalities they detected. A detailed examination of the characteristics of children with reactive attachment disorders, compared with those diagnosed with pervasive developmental disorders who live in stable, secure environments, will be useful a start for exploring this question further.

Another aspect of the functional versus organic dichotomy in the $D S M-I V$ is that the disturbed attachment behaviors are not solely the result of developmental delays. However, if a child has delays and aberrant social behavior, how do we know that the delay causes the aberrant social behavior? In fact, as we know from children raised in impoverished institutions and in extremes of deprivation, significant cognitive impairments are likely to occur along with disordered attachments (Provence \& Lipton, 1962; Rosenberg, Pajer, \& Rancurello, 1992). We also know that children in institutions that are more stimulating and developmentally sensitive have normal intelligence but disordered attachments (Tizard \& Hodges, 1978). Essentially, the $D S M-I V$ criterion about cognitive delays is another manifestation of the attempt to limit attachment disorders to children with an intact central nervous system. There seems to be little justification for presuming that children with cognitive delays or mental retardation cannot also have attachment disorders. Perhaps what could be included instead is a requirement that children with attachment disorders have a level of cognitive abilities of at least 10 to 12 months, since this would ensure that they are cognitively capable of having a preferred attachment figure.

Finally, there is the problem of the "reactive" label invoking parent blaming. Maltreatment by parents is unmistakably related to problem behaviors, unhappiness, and psychiatric disorders in children. Still, histories of abuse or neglect may not be known, and the problems associated with adequately defining emotional maltreatment, which may be an important contributor to attachment disorders, are numerous and complex (Cicchetti, 1991; McGee \& Wolfe, 1991). Volkmar (in press) has pointed out that focusing on parental maltreatment complicates determining the behavioral features that may occur in the absence of severe adversity. Furthermore, the arbitrariness with which maltreatment is identified in the clinical and legal worlds is not sufficiently reliable for diagnostic criteria. Finally, pejorative labeling of parents, even implicitly, is unlikely to be helpful and runs counter to the prevailing clinical practice in infant mental health of evaluating the fit between parent and infant, with attention to the strengths and weaknesses each partner brings to their relationship. On balance, there is little justification for singling out attachment disorders and specifying only their etiology in classification systems that are explicitly phenomenologic. The innumerable complexities inherent in determining the etiology of psychiatric disorders are no less true of attachment disorders.

\section{Is It Attachment?}

Perhaps the most striking characteristic of both $D S M-I V$ and ICD-10 criteria for disorders of attachment is their depiction of the disorders in terms of socially aberrant behavior in general rather than focusing more specifically on attachment behaviors per se. The $D S M-I V$ emphasizes a failure to initiate or respond to social interactions across a range of relationships (Appendix A), and the ICD-10 similarly focuses on contradictory or ambivalent social responses that extend across social situations (Appendix B). This emphasis has the effect of deemphasizing attachment in attachment disorders.

Bowlby $(1969,1988)$ has described attachment as a behavioral control system concerned with maintaining infants' safety and survival through access to the care, nurturance, and especially, protection given by an attachment figure. Feelings of security, safety, and value become associated with the qualitative features of the infant's relationship with attachment figure. Between the ages of 1 and 3 years, the attachment behavioral system is responsible for motivating a child to attain felt security (Bischof, 1975), initially through physical proximity to the attachment figure when needed. As representational processes mature during the second and third years, literal proximity to the caregiver becomes gradually less necessary to attain felt security, and psychological availability of the attachment figure becomes even more pronounced.

The attachment system and the exploratory system operate in tandem within the child to produce an attachment-exploration balance; that is, at times when the child feels secure, he or she is motivated to explore. If the child becomes frightened in the course of exploration, however, the motivation to explore diminishes as the motivation to seek proximity and comfort intensifies. Disruptions of this balance represent disturbances in the use of the attachment figure as a secure base from which to explore with confidence or disturbances in the use of the attachment figure as a safe haven (Ainsworth, 1967) to which to retreat in times of danger. The Strange Situation Procedure developed by Ainsworth and her colleagues (Ainsworth, Blehar, Waters, \& Wall, 1978) makes it possible to observe the child's attachment-exploration balance with a particular caregiver. This perspective has been elaborated and clarified by over 2 decades of empirical research involving attachment classifications derived from the organization of the child's behavior and the Strange Situation (see Bretherton \& Waters, 1985; Sroufe, 
1988; Zeanah \& Emde, 1994, for reviews) and has great value in the clinical arena as well.

Controversies about the interpretation of research using the Strange Situation Procedure (see Lamb, Thompson, Gardner, Scarnov, \& Estes, 1984; Sroufe, 1988) notwithstanding, there are a number of well-replicated findings from attachment research that can usefully be applied to clinical disorders of attachment. Despite an enormous developmental literature with careful operationalization of attachment in these terms, there is little attention in the nosologies to the broad range of behaviors that might index disordered attachment relationships. Drawing on clinical experience and developmental attachment research, Zeanah et al. (1993) have proposed several domains of child behavior expressed toward caregivers that ought to be evaluated in considering disordered attachment. These include lack of affection or promiscuous affection; absent, odd, or ambivalent comfort-seeking from the caregiver; excessive dependence or failure to use the supportive presence of the caregiver when needed; noncompliance or overcompliance; excessively inhibited exploratory behavior or exploration without checking back; oversolicitous and inappropriate caregiving of the excessively bossy and punitive attempts by the child to control the parent's behavior; and failure to reestablish affective contact after brief separations including ignoring, angry, or unaffectionate responses. Although some of these behaviors are indices of insecure attachments, they become clinical indicators only at extremes of the normal distribution. When these behaviors represent extremes, and when they indicate together a pattern of the child's behavior expressed toward attachment figures, these aspects of child behavior may be useful in identifying disordered attachments ( see case examples in Zeanah et al., 1993, \& Lieberman \& Zeanah, 1995).

Another problem is that, although developmental research has demonstrated clearly that attachment may vary across different relationships, the $D S M-I V$ and the ICD-10 emphasize the continuity of socially aberrant behavior across contexts. This emphasis may reflect an attempt to distinguish attachment disorders from relational problems that are coded as $\mathrm{V}$ codes rather than as Axis I disorders in DSM-IV (Volkmar, in press). Nevertheless, in addition to broad support from developmental research, clinical experience also suggests that an infant may have a disordered attachment relationship with one particular caregiver without manifesting severely deviant or symptomatic behavior outside of the context of that relationship. A broader definition of attachment disorders would make it possible to include children who do not have obviously symptomatic behavior with day-care providers, preschool teachers, or peers, for example.

Certainly, peer relations do not appear to be central to a conceptualization of the disorders as disturbances of attachment. Even if research indicates that disturbed peer relations are common in children with attachment disorders, this probably should be an associated feature, with disturbed behaviors in attachment relationships forming the core features of the disorders.

All of this contributes to the impression that the disorders as described by the $D S M-I V$ and ICD-10 are more maltreatment syndromes rather than attachment disorders. The emphasis on maltreatment is evident in the data bases used to develop the criteria, in the explicit or implicit emphasis on parental mal- treatment, and in the description of general problems with deviant social behaviors in general rather than a more specific focus on attachment behaviors. Defining attachment disorders by using criteria that are drawn primarily from children who have been physically abused, who have suffered extremes of deprivation, and who have been deprived in institutions limits the disorders to children in extreme situations and does not account for children who are in stable, albeit unhealthy, relationships without overt abuse or neglect. Focusing on unusual social behaviors across a range of situations tends to restrict the diagnosis of the disorder to severely mistreated children. Although maltreatment is probably one important contributor to some types of attachment disorders, it is neither necessary nor sufficient to make the diagnosis. Similarly, not all maltreated children will exhibit attachment disorders. Focusing on disordered attachment behaviors rather than on maltreatment avoids the problem of attempting to determine what constitutes emotional maltreatment, recognizes that attachment is only one among several possible sequela of maltreatment, and recognizes that maltreated children have diverse outcomes.

\section{Is It a Disorder?}

Both DSM-IV (Volkmar, in press) and the ICD-10 (World Health Organization, 1992) note the lack of direct validity data about disorders of attachment. They justify inclusion of this group of disorders provisionally because of their obvious clinical importance and because the signs and symptoms cannot be explained by other disorders. One of the difficulties for the traditional nosologies is that, as noted earlier, attachment disorders are relational in nature. $A$ long tradition in science and medicine, exemplified by the $D S M-I V$ and the ICD-10, defines disorders within individuals. A newer but less well-accepted scientific paradigm, represented by systems theory, defines disorders between, rather than within, individuals.

A variant of the systems approach has been proposed by a group of developmental investigators (Sameroff \& Emde, 1989). For children under 3 years of age, they proposed a continuum of dysfunctional parent-infant relationships, culminating in the most severe dysfunctions, which they designated "relationship disorders." These are disorders between rather than within individuals, which involve rigid patterns of maladaptive interactions and which are associated with a failure to attain age- and stage-appropriate developmental tasks for one or both partners (Anders, 1989). The rationale for considering psychopathology in terms of relationship disorders is the assertion that most clinical problems in infancy are firmly rooted in important relationships and that intervening in these relationships is what helps clinically (Emde \& Sameroff, 1989). Relationship disorders may result from, lead to, co-occur with, or be independent from individual psychopathology and symptomatology (Zeanah, 1994).

Whether this proposed conceptualization reflects a paradigmatic shift or a passing fad remains to be seen. The Zero-to-Three Task Force on Diagnostic Classification in Infancy (1994) has incorporated both a parent-infant relationship global assessment scale and a specific axis of relationship disorders into its system. Validation of these approaches is needed.

All of this is relevant to a consideration of attachment disorders 
because they are invoked to describe a disorder involving the child's primary relationships. Nevertheless, it is not essential to conceptualize attachment disorders as relationship disorders. Symptoms and signs of attachment disorders need not be manifest across all or even multiple contexts; that is, at least some types of disordered attachment behaviors and symptomatology may exist within an individual infant but be elicited only in the context of the primary caregiving relationship. A young child who allows a day care center staff member to comfort him somewhat when distressed but who does not seek comfort from his primary caregiver when distressed may have an attachment disorder. Note that $D S M-I V$ criteria would not permit diagnosing this child with an attachment disorder because his comfort-seeking behavior is variable in different relationships.

One of the most important difficulties in considering a diagnosis of attachment disorders is the problem of caseness, that is, when signs and symptoms of a disorder are severe enough to warrant a diagnosis. The difficulty arises in part because the orientation to the first 3 years of life, as well as the vast majority of research in developmental psychopathology in this period, has been framed in terms of risk and protective factors as they impact developmental trajectories. The risk and protective factors approach invites consideration of symptoms, not in terms of current distress but instead in terms of whether the infant's current behaviors are probabilistically related to impairment at a later date. This has been an enormously valuable approach for clinicians and researchers, and one that should be preserved, to the degree that it is possible, in determining caseness of attachment disorders. Before discussing what a case of disordered attachment is, it is important to revisit the distinction between insecure and disordered attachments.

It is important not to have caseness of attachment disorders tied directly to Strange Situation classifications of insecure attachments (Ainsworth et al., 1978) for a number of reasons (Zeanah \& Emde, 1994). The Strange Situation Procedure was designed to classify infant attachment among groups of infants in a research setting rather than to diagnose a particular infant in a clinical setting. Clinicians must be concerned with behaviors in naturalistic rather than laboratory settings, and the links between infant behaviors in the Strange Situation Procedure and those in naturalistic settings are too variable for individual infants to be useful clinically. It is also problematic to over-rely on separation and reunion behaviors, which as noted earlier, constitute only one aspect of attachment relationships salient for evaluating attachment disorders (Gaensbauer \& Harmon, 1982). In addition, behavior of the adult caregiver is constrained in the Strange Situation, making evaluation of adultchild interaction problematic. Consider, for example, that infants who avoid their caregivers in the Strange Situation Procedure have not been observed to avoid them in naturalistic settings (Ainsworth et al., 1978). Finally, as Sroufe (1988) has emphasized, insecure classification in the Strange Situation is not indicative of psychopathology but risk for psychopathology.

If there is a classification that most approaches psychopathology on its own, it is the disorganized-disoriented classification (Main \& Solomon, 1986, 1990). Two lines of evidence support this association. First, the proportion of infants classified as disorganized is clearly increased in high-risk samples of infants (Carlson, Cicchetti, Barnett, \& Braunwald, 1989; DeMulder \&
Radke-Yarrow, 1991; Hubbs-Tait et al., 1991; Lyons-Ruth, Repacholi, \& Silva, 1991; O'Connor, Sigman, \& Brill, 1987; Rodning, Beckwith, \& Howard, 1989). Second, preliminary evidence suggests that it may be strongly linked to disruptive behavior disorders in later childhood (Lyons-Ruth, Alpern, \& Repacholi, 1993). Still, determining how even this classification relates to caseness is problematic for three reasons. First, there is a lack of data about the distinctive naturalistic correlates of infants classified disorganized or disoriented in the Strange Situation. Second, the classification is found in roughly $20 \%$ of infants in nonclinical samples, suggesting that it is not synonymous with caseness. Finally, the classification itself is determined by a continuous rating scale that reflects a judge's certainty about the presence of disorganized or disoriented attachment behavior rather than the severity of disorganized or disoriented behavior. Because there are no data examining adaptation of children with different levels of disorganized or disoriented attachment behavior in the Strange Situation, it is not clear how many children at different levels satisfy the requirements of caseness.

Disorders of attachment ought to represent more profound and pervasive disturbances in the child's feelings of safety and security than are reflected by insecure attachments. If insecure attachment is not synonymous with disordered attachment, then one must ask, when is a child's attachment behavior indicative of disordered attachment? In other words, at what point, if any, does a risk factor (insecure attachment) become a case (attachment disorder)? Zeanah et al. (1993) have proposed that attachment problems become psychiatric disorders when emotions and behaviors displayed in attachment relationships are so disturbed as to indicate, or substantially to increase the risk of, persistent distress or disability in the infant. This definition maintains a focus on disturbed feelings and behaviors within an individual, attempts to preserve risk as a legitimate aspect of the diagnosis, and makes persistent distress and disability core features of the disorder.

Admittedly, this definition leaves wide latitude for clinical judgment about a particular case, which at the current state of the art is probably appropriate for two related reasons. First, as noted previously, there are no data available for evaluating the usefulness of any of the criteria. Second, there are no standardized and validated measures for assessing attachment disorders nor methods for quantifying symptoms of attachment disorders. Parent report measures of psychiatric symptoms and disorders are often used for children less than 10 years of age, but these seem especially unlikely to be helpful in cases of attachment disorders which are so closely tied to the relationship between parent and child. Possibly, an observational or clinical interview instrument for assessing behaviors to be salient for attachment disorders would be most desirable, but no such measure exists at present. Proposing arbitrary cutoff levels for symptoms other than the clinicians' estimation of sufficient degree of or risk for persistent distress and disability seems ill advised. Most of the disorders in the DSM and the ICD, in fact, allow latitude for clinical judgment with regard to caseness.

There is still the question of whether insecure attachments ever can be considered disorders of attachment. If the fact that $40 \%$ to $50 \%$ of infants in low-risk samples are classified insecure in the Strange Situation is taken seriously, then it is likely that 
each category of insecure attachment represents a broad range of adaptive functioning. There are undoubtedly extremes of maladaptation that indicate psychopathology at some point within the range of each type of insecurity. It is possible that extremes of avoidant or resistant behavior during reunions in the Strange Situation procedure, for example, represent "cases" of disordered attachment, but this has not been examined empirically. In summary, disordered attachments are always insecure attachments (or the absence of attachments altogether), but insecure attachments are likely to be disordered only at the extremes of each type.

\section{Alternative Conceptualizations}

Several alternative conceptualizations to disordered attachment have appeared besides those appearing in the official nosologies. Greenspan and his colleagues (Greenspan, 1981; Greenspan \& Lieberman, 1988; Greenspan \& Lourie, 1981) considered attachment disorders as phase-specific disturbances within their developmental-structuralist framework Call ( 1980 , 1983), on the other hand, considered attachment disorders from the psychodynamic perspective of the developmental processes of separation and individuation. These two approaches have provided alternative conceptualizations to the criteria in $D S M-I V$ standard nosologies by focusing disordered attachment more specifically on the infant's behavior with the primary attachment figure and by including a broader focus than responses to maltreatment alone. Nevertheless, neither the Greenspan nor the Call approaches to attachment disorders incorporated findings from developmental attachment research in either their definitions or in the criteria used to operationalize them, neither has had the reliability or validity of their criteria assessed, and neither has won widespread acceptance.

In contrast to these approaches, Lieberman and Pawl (1988, 1990) drew upon developmental attachment research in defining attachment disorders as secure base distortions. They described three patterns of disordered attachment and illustrated each of them with clinical vignettes. The first, recklessness and accident proneness, described infants who failed to check back with their caregivers at times when their infants' attachment systems ought to have been aroused. In the second type, inhibition of exploration, infants seemed unwilling to venture away from the secure base that their caregivers were to provide. Finally, in the third pattern, precocious competence in self-protection, infants seemed to have inverted the secure base so that they were excessively self-reliant and providing care and protection to the parent. This system of classifying attachment disorders, although not fully developed in the form of criteria, formed the foundation for the expanded system of classifying attachment disorders described by Zeanah, Mammen, and Lieberman (1993) and more recently by Lieberman and Zeanah (1995).

This most recent alternative system for classifying disordered attachment also was created from clinical observation but also with the explicit attempt to fashion criteria for attachment disorders that incorporated the major findings of developmental attachment research. The system of classification identifies three different major types of disorders of nonattachment, dis- ordered attachments, and disrupted attachment disorder. These are described briefly later ( see Table 1).

Nonattached attachment disorder describes infants who do not exhibit a preferred attachment to anyone, despite having attained a cognitive age of 10 to 12 months. There are two types, an emotionally withdrawn, inhibited subtype and an indiscriminately social subtype. These two subtypes are similar to the $D S M-I V$ and ICD-10 descriptions of attachment disorders.

Disordered attachments, on the other hand, are distortions in the child's use of the caregiver as a secure base from which to explore the world and a safe haven to which to return in times of danger. What is characteristic of secure-base distortions is that the symptomatic behaviors are relationship-specific and confined to the disordered attachment relationship. The young child who is excessively clingy and extremely inhibited about exploring typifies an attachment disorder with inhibition. The child who moves away from the caregiver too easily without checking back even in times of danger and who exhibits a pattern of reckless and dangerous behavior characterizes attachment disorder with self-endangerment. Finally, if the attachment relationship is inverted so that the child tends to and worries excessively about the emotional wellbeing of the attachment figure to a developmentally inappropriate degree, then disordered attachment with role reversal ought to be considered.

Disrupted attachment disorder describes the grief response of young children who lose their major attachment figure. These reactions were originally described by Robertson and Robertson's (1989) work with children separated from their parents. Because of the central importance of the attachment figure in the first 3 years of life, the loss of an attachment figure at this time may be qualitatively different than if the loss occurs at other points in the life cycle.

Each of these types of attachment disorders has specific criteria to be used in its identification. What is characteristic of this system is that it is more specifically focused on the child's attachment behaviors and attachment relationships rather than on social behaviors in a variety of contexts. Although the criteria in this system have not yet been validated, the criteria are operationalized sufficiently to permit such investigations.

It is likely that focusing disordered attachment more specifcally on relationship disturbances between infants and parents

Table 1

An Alternative Conceptualization of Disorders of Attachment

\begin{tabular}{ll}
\hline \multicolumn{1}{c}{ Disorder } & \multicolumn{1}{c}{ Alternative conceptualization } \\
\hline Nonattachment & $\begin{array}{l}\text { Nonattachment with indiscriminate } \\
\text { sociability } \\
\text { Nonattachment with emotional } \\
\text { withdrawal } \\
\text { Disordered attachment with inhibition } \\
\text { Disordered attachment with self- } \\
\text { endangerment } \\
\text { Disordered attachment }\end{array}$ \\
Disrupted attachment & Grief reaction following loss \\
\hline
\end{tabular}

Note. From Child and Adolescent Psychiatric Clinics of North America, by A. Lieberman and C. H. Zeanah, 1995, Philadelphia: W. B. Saunders. Copyright 1995 by W. B. Saunders. Adapted with permission. 
and less specifically on aberrant social behavior would mean that attachment disorders will become applicable to a larger number of symptomatic young children. For example, in the seven cases of infants with disturbed attachment relationships presented by Zeanah, Mammen, and Lieberman (1993), only one could be diagnosed with attachment disorders using DSM$I V$ and ICD-10 criteria. Attention to attachment behaviors in these symptomatic infants also is useful in focusing treatment efforts.

\section{Summary}

Several related theses have been set forth in this article regarding disorders of attachment in early childhood. First, the criteria used to described attachment disorders in $D S M-I V$ and ICD-10 more properly define maltreatment syndromes than attachment disorders. They implicitly (ICD-10) or explicitly $(D S M-I V)$ require parental maltreatment or absence of stable caregiving. As such, their clinical usefulness is diminished by the narrowness of the population to whom they can be usefully applied. By incorporating research findings and definitions from basic developmental research, it is possible to modify the criteria and to describe the clinical features of a larger group of children who are in stable but disordered attachment relationships (Zeanah, Mammen, \& Lieberman, 1993). Furthermore, these assertions are testable in groups of high-risk and clinicreferred infants.

Second, in addition to broadening the criteria of attachment disorders beyond maltreatment, the criteria for attachment disorders should be focused more specifically on the child's attachment-exploration balance and use of the attachment figure as a secure base and a safe haven. These behaviors provide clinically apparent and meaningful guidelines to the evaluating the construct of attachment in naturalistic settings and avoid the confusion introduced by diffusing the features of the disorder to broad indices of social functioning. By focusing more specifcally on infant-caregiver attachment, the disorder is broadened to include not only children with no attachment relationships but also those with extremely disturbed attachment relationships with their caregivers.

Third, the requirement that disordered attachment be present across social contexts should be dropped in recognition that attachment, whether disordered or not, may be expressed differentially in different relationships. It is possible to define a disorder within an individual even if its expression is not crosscontextual. This perspective requires acknowledgement of the child's capacity to construct differing relationships with different caregiving adults, which has been repeatedly demonstrated in developmental research.

Fourth, as noted repeatedly in this article, the absence of efforts to validate these disorders, using any of the available criteria, is currently a major problem for the field. The validity data relevant to all classifications of attachment disorders are all indirect, and the effort to validate attachment disorders should be a top research priority. As a part of that effort, these disorders must be distinguished from insecure attachment and from other types of psychiatric disorders affecting young children. This may require development of structured interviews and observational rating paradigms to facilitate evaluation of patterns of the child's behavior relevant to attachment disorders.

Fifth, another area in need of attention is how to distinguish clearly between insecure and disordered attachment. Another way of framing the question is, When do risk factors (insecure attachments) become clinical disorders (attachment disorders)? This is the question of caseness described earlier, and in the future, investigators should address this question empirically. At present, it is likely that a consensus of clinical judgment about what constitutes a case of attachment disorder will be most useful as a starting point.

Finally, integration of findings from developmental attachment research into criteria for clinical disorders of attachment may enrich the perspective on important clinical problems and also provide us with even more pressing questions for developmental research.

\section{References}

Aber, J. L., \& Allen, J. ( 1987). Effects of maltreatment on young children's socioemotional development: An attachment theory perspective. Developmental Psychology, 23, 406-414.

Aber, J. L., \& Cicchetti, D. (1984). The socio-emotional development of maltreated children: An empirical and theoretical analysis. In H. Fitzgerald, B. Lester, \& M. Yogman (Eds.), Theory and research in behavioral pediatrics (Vol. 2, pp. 147-205). New York: Plenum Press.

Ainsworth, M. D. S. ( 1967). Infancy in Uganda: Infant care and the growth of attachment. Baltimore: Johns Hopkins University Press.

Ainsworth, M. D. S., Blehar, M. C., Waters, E., \& Wall, S. (1978). Patterns of attachment: A psychological study of the Strange Situation. New York: Basic Books.

American Psychiatric Association. (1968). Diagnostic and statistical manual of mental disorders (2nd ed.). Washington, DC: Author.

American Psychiatric Association. (1980). Diagnostic and statistical manual of mental disorders ( $3 \mathrm{rd}$ ed.). Washington, DC: Author.

American Psychiatric Association. (1987). Diagnostic and statistical manual of mental disorders (3rd ed., rev.). Washington, DC: Author.

American Psychiatric Association. (1994). Diagnostic and statistical manual of mental disorders (4th ed.). Washington, DC: Author.

Anders, T. F. (1989). Clinical syndromes, relationship disturbances, and their assessment. In A. J. Sameroff \& R. N. Emde (Eds.), Relationship disturbances in early childhood (pp. 125-144). New York: Basic Books.

Arend, R., Gove, F., \& Sroufe, L. A. (1979). Continuity of individual adaptation from infancy to kindergarten: A predictive study of ego resiliency and curiosity in preschoolers. Child Development, 50, 950959.

Bates, J. E., Maslin, C. A., \& Frankel, K. A. (1985). Attachment security, mother-child interaction, and temperament as predictors of behavior-problem ratings at age three years. In I. Bretherton \& E. Waters (Eds.), Growing points in attachment theory and research. Monographs of the Society for Research in Child Development, 50 (Serial No. 209), 167-193.

Bischof, N. A. (1975). A systems approach toward the functional connections of fear and attachment. Child Development, 46, 801-817.

Bowlby, J. (1951). Maternal care and mental health. Geneva, Switzerland: World Health Organization.

Bowlby, J. (1969). Attachment and loss: Attachment. New York: Basic Books.

Bowlby, J. (1973). Attachment and loss: Separation. New York: Basic Books.

Bowlby, J. (1980). Attachment and loss: Loss. New York: Basic Books. 
Bowlby, J. ( 1988). A secure base. New York: Basic Books.

Bretherton, J., \& Waters, E. (Eds.). ( 1985). Growing points of attachment theory and research. Monographs of the Society for Research in Child Development, 50(Serial No. 209).

Call, J. D. (1980). Attachment disorders of infancy. In H. I. Kaplan, A. M. Freedman, \& B. J. Sadock (Eds.), Comprehensive textbook of psychiatry (pp. 2586-2597). Baltimore: Williams \& Wilkins.

Call, J. D. (1983). Toward a nosology for psychiatric disorders in infancy. In J. Call, E. Galenson, \& R. L. Tyson (Eds.), Frontiers of infant psychiatry (pp. 117-128). New York: Basic Books.

Carlson, V., Cicchetti, D., Barnett, D., \& Braunwald, K. ( 1989). Finding order in disorganization: Lessons for research from maltreated infants attachments to their caregivers. In D. Cicchetti \& V. Carlson (Eds.), Child maltreatment: Theory and research on the causes and consequences of child abuse and neglect (pp. 494-528). Cambridge, MA: Cambridge University Press.

Cassidy, J. (1988). Child-mother attachment and the self at age six. Child Development, 57, 331-337.

Chapin, H. D. (1915). Are institutions for infants necessary? Journal of the American Medical Association, 64, 1-3.

Cicchetti, D. (1991). Defining psychological maltreatment: Reflections and future directions. Development and Psychopathology, 3, 1-2.

Curtiss, S. (1977). Genie: A psycholinguistic study of a modern-day "wild child." London: Academic Press.

DeMulder, E. K., \& Radke-Yarrow, M. (1991). Attachment in affectively ill and well mothers: Concurrent behavioral correlates. Development and Psychopathology, 3. 227-242.

Easterbrooks, A., \& Goldberg, W. (1990). Security of toddler-parent attachment: Relation to children's sociopersonality functioning during kindergarten. In M. T. Greenburg, D. Cicchetti, \& E. M. Cummings (Eds.), Attachment in the preschool years (pp. 221-244). Chicago: University of Chicago Press.

Emde, R. N., \& Sameroff, A. J. (1989). Understanding early relationship disturbances. In A. J. Sameroff \& R. N. Emde (Eds.), Relationship disturbances in early childhood. New York: Basic Books.

Erickson, M. F., Sroufe, L. A., \& Egeland, B. ( 1985). The relationship between quality of attachment and behavior problems in preschool in a high-risk sample. Monographs of the Society for Research in Child Development, 50(Serial No. 209), 147-166.

Fagot, B. L., \& Kavanagh, K. (1990). The prediction of antisocial behavior from avoidant attachment classifications. Child Development, 61, 864-873.

Gaensbauer, T. J., \& Harmon, R. J. (1982). Attachment in abused/ neglected and premature infants. In R. N. Emde \& R. J. Harmon (Eds.), The development of attachment and affiliative systems (pp. 263-280). New York: Plenum Press.

Gaensbauer, T., \& Sands, K. (1979). Distorted affective communications in abused/neglected infants and their potential impact on caregivers. Journal of the American Academy of Child and Adolescent Psychiatry, 18. 236-250.

George, C., \& Main, M. (1979). Social interactions in young abused children: Approach, avoidance, and aggression. Child Development. 50, 306-318.

Goldfarb, W. (1945). Effects of psychological deprivation in infancy and subsequent stimulation. American Journal of Psychiatry, 102. 18-33.

Greenspan, S. I. ( 1981 ). Psychopathology and adaptation in infancy and early childhood: Principles of clinical diagnosis and preventive intervention. (Clinical Infant Reports, 1). New York: International Universities Press.

Greenspan, S. I., \& Lieberman, A. (1988). A clinical approach to attachment. In J. Belsky \& T. Nezworski (Eds.), Clinical implications of attachment (pp. 387-424). Hillsdale, NJ: Erlbaum.

Greenspan, S. I., \& Lourie, R. (1981). Developmental structuralist ap- proach to the classification of adaptive and pathologic personality organization: Application to infancy and early childhood. American Journal of Psychiatry, I38, 725-735.

Hirshfield, R., \& Goodwyn, F. ( 1988) Mood disorders. In J. A. Talbott, R. E. Hales, \& S. Yudofsky (Eds.), The American Psychiatric Press textbook of psychiatry (pp. 403-442). Washington, DC: American Psychiatric Press.

Hubbs-Tait, L., Eberhart-Wright, A., Ware, L., Osofsky, J., Yockey, W., \& Fusco, J. (1991). Maternal depression and infant attachment: Behavior problems at 54 months in children of adolescent mothers. Paper presented at the Biennial Meeting of the Society for Research in Child Development, Seattle, WA.

Koluchova, J. (1972). Severe deprivation in twins: A case study. Journal of Child Psychology and Psychiatry, 13, 107-114.

Lamb, M., Thompson, R. A., Gardner, W. P., Chamov, E. L., \& Estes, D. (1984). Security of infantile attachment as assessed in the "Strange Situation": Its study and biological interpretation. The Behavioral and Brain Sciences, 7, 127-171.

Lewis, M., Feiring, C., McGuffog, C., \& Jaskir, J. (1984), Predicting psychopathology in six-year-olds from early social relations. Child Development, 55, 123-136.

Lieberman, A. F., \& Pawl, J. (1988). Clinical applications of attachment theory. In J. Belsky \& T. Nezworski (Eds.), Clinical implications of attachment (pp. 327-351). Hillsdale, NJ: Erlbaum.

Lieberman, A. F., \& Pawl, J. (1990). Disorders of attachment and secure base behavior in the second year of life: Conceptual issues and clinical intervention. In M. T. Greenburg, D. Cicchetti, \& E. M. Cummings (Eds.), Attachment in the preschool years (pp. 121-160). Chicago: University of Chicago Press.

Lieberman, A. F., \& Zeanah, C. H. (1995). Disorders of attachment. In K. Minde (Ed.), Infant psychiatry, child and adolescent clinics of North America (pp. 571-588). Philadelphia: Lippincott.

Lyons-Ruth, K., Alpern, L., \& Repacholi, B. (1993). Disorganized infant attachment classification and maternal psychosocial problems as predictors of hostile-aggressive behavior in the preschool classroom. Child Development, 64, 572-585.

Lyons-Ruth, K., Repacholi, B., McLeod, S., \& Silva., E. (1991). Disorganized attachment behavior in infancy: Short-term stability, maternal and infant correlates, and risk-related subtypes. Development and Psychopathology, 3, 377-396.

Main, M., \& George, C. (1985). Responses of abused and disadvantaged toddlers to distress in agemates: A study in the day-care setting. Developmental Psychology, 21, 407-412.

Main, M., \& Solomon, J. (1986). Discovery of an insecure, disorganized/disoriented attachment pattern: Procedures, findings, and implications for the classification of behavior. In M. Yogman \& T. B. Brazelton (Eds.), Affective development in infancy (pp. 95-124). Norwood, NJ: Ablex.

Main, M., \& Solomon, J. (1990). Procedures for identifying infants as disorganized/disoriented during the Ainsworth Strange Situation. In M. T. Greenburg. D. Cicchetti, \& E. M. Cummings (Eds.), Attachment in the preschool years (pp. 121-160). Chicago: University of Chicago Press.

Matas, L., Arend, R. A., \& Sroufe, L. A. (1978). Continuity of adaptation in the second year: The relationship between quality of attachment and later competence. Child Development, 49, 547-556.

McGee, R., \& Wolfe, D. A. (1991). Psychological maltreatment: Toward an operational definition. Development and Psychopathology, 3. 3-18.

Mueller, E., \& Silverman, N. (1989). Peer relations in maltreated children. In D. Cicchetti \& V. Carlson (Eds.), Child maltreatment: Theory and research on the causes and consequences of child abuse and neglect. Cambridge, MA: Cambridge University Press.

O'Connor, M. J., Sigman, M., \& Brill, N. (1987). Disorganization of 
attachment in relation to maternal alcohol consumption. Journal of Consulting and Clinical Psychology, 55, 831-836.

Powell, G. F., Low, J. F., \& Speers, M. A. (1987). Behavior as a diagnostic aid in failure to thrive. Journal of Developmental and Behavioral Pediatrics, 8, 18-24.

Provence, S., \& Lipton, R. C. (1962). Infants reared in institutions. New York: International Universities Press.

Richters, M. M., \& Volkmar, F. (1994). Reactive attachment disorder: Case reports. Journal of the American Academy of Child and Adolescent Psychiatry, 33, 328-332.

Robertson, J., \& Robertson, J. (1989). Separations and the very young. London: Free Association Books.

Rodning, C., Beckwith, L., \& Howard, J. (1989). Characteristics of attachment organization in prenatally drug-exposed toddlers. Development and Psychopathology, 1, 277-289.

Rosenberg, D. R., Pajer, K., \& Rancurello, M. (1992). Neuropsychiatric assessment of orphans in one Romanian orphanage. Journal of the American Medical Association. 268, 3489-3490.

Sameroff, A. J., \& Emde, R. N. (Eds.). (1989). Relationship disturbances in early childhood. New York: Basic Books.

Skeels. (1966). Adult status of children with contrasting life experiences. Monographs of the Society for Research in Child Development. $3 I$ (Serial No. 105).

Skuse, D. (1984). Extreme deprivation in early childhood-I. Diverse outcomes for three siblings from an extraordinary family. Journal of Child Psychology, Psychiatry, and Allied Disciplines, 25, 523-541.

Solomon, J., George, C., \& Ivins, B. (1989, April). Mother-child interaction in the home and security of attachment at age six. Paper presented at the Biennial Meeting of the Society for Research in Child Development, Baltimore.

Spitz, R. (1945). Hospitalism: An inquiry into the genesis of psychiatric conditions in early childhood. The Psychoanalytic Study of The Child, 1, 53-74.

Spitz, R. (1946). Anaclitic depression: An inquiry into the genesis of psychiatric conditions in early childhood-II. The Psychoanalytic Study of The Child, 2, 313-342.

Spitzer, R., \& Cantwell, D. (1980). The DSM-III classification of the psychiatric disorders of infancy, childhood, and adolescence. Iournal of the American Academy of Child and Adolescent Psychiatry, 19. 356-370.

Sroufe, L. A. (1983). Infant-caregiver attachment and patterns of adaptation in preschool: The roots of maladaptation and competence. In M. Perlmutter (Ed.), Minnesota Symposium in Child Psychology (Vol. 16, pp. 41-81), Hillsdale, NJ: Erlbaum.

Sroufe, L. A. (1988). The role of infant-caregiver attachment in development. In J. Belsky \& T. Nezworski (Eds.), Clinical implications of attachment (pp. 18-40). Hillsdale, NJ: Erlbaum.

Suess, G. J., Grossman, K. E., \& Sroufe, L. A. (1992). Effects of infant attachment to mother and father on quality of adaptation in preschool: From dyadic to individual organization of self. International Journal of Behavioral Development, 15, 43-65.

Thompson, A. M. (1986). Adam-A severely deprived Colombian orphan: A case report. Journal of Child Psychology and Psychiatry, 27. 689-695.

Tizard, B., \& Hodges, J. (1978). The effect of early institutional rearing on the development of eight-year-old children. Journal of Child Psychology and Psychiatry, 19, 99-118.

Tizard, B., \& Rees, J. (1974). A comparison of the effects of adoption, restoration of the natural mother, and continued institutionalization on the cognitive development of four-year-old children. Child Development, 45, 92-99.

Tizard, B., \& Rees, J. (1975). The effect of early institutional rearing on the behavior problems and affectional relationships of four-yearold children. Journal of Child Psychology and Psychiatry, 27, 61-73.

Troy, M., \& Sroufe, L. A. (1987). Victimization among preschoolers: Role of attachment relationship history. Journal of the American Academy of Child and Adolescent Psychiatry, 26, 166-172.

Volkmar, F. (in press). Reactive attachment disorders: Issues for DSMIV. DSM-IV source book. Washington, DC, American Psychiatric Association.

Wartner, U. G., Grossman, K., Fremmer-Bombik, E., \& Suess, G. (1994). Attachment patterns at age six in South Germany: Predictability from infancy and implications for preschool behavior. Child Development, 65, 1014-1027.

Waters, E., Wippman, J., \& Sroufe, L. A. (1979). Attachment, positive affect, and competence in peer group: Two studies in construct validation. Child Development, 50, 821-829.

World Health Organization. (1978). Medical disorders: Glossary and guide to their classification in accordance with the ninth revision of the International Classification of Diseases. Geneva, Switzerland: Author.

World Health Organization. (1992). The ICD-10 classification of mental and behavioral disorders: Clinical descriptions and diagnostic guidelines. Geneva, Switzerland: Author.

Zeanah, C. H. (1994). Critical notice: Relationship disturances in early childhood. Journal of Child Psychology, Psychiatry, and Allied Disciplines, 35, 383-385.

Zeanah, C. H., \& Emde, R. N. (1994). Attachment disorders in infancy. In M. Rutter, L. Hersov, \& E. Taylor (Eds.), Child and adolescent psychiatry: Modern approaches (pp. 490-504). Oxford, England: Blackwell.

Zeanah, C. H., Mammen, O., \& Lieberman, A. (1993). Disorders of attachment. In C. H. Zeanah (Ed.), Handbook of infant mental health (pp. 332-349). New York: Guilford Press.

Zero-To-Three Task Force on Diagnostic Classification in Infancy. (1994). Diagnostic classification of mental health and developmental disorders of infancy and early childhood. Arlington, VA: Author. 


\section{Appendix A}

\section{$D S M-I V$ Criteria for Reactive Attachment Disorder}

\section{Reactive Attachment Disorder}

Criterion A. Markedly disturbed and developmentally inappropriate social relatedness in most contexts, beginning before age 5, as evidenced by either $\mathrm{A} 1$ or $\mathrm{A} 2$ :

1. Persistent failure to initiate or respond in a developmentally appropriate fashion to most social interactions, as manifest by excessively inhibited, hypervigilant, or highly ambivalent and contradictory responses (e.g., the child may respond to caregivers with a mixture of approach, avoidance, and resistance to comforting or may exhibit frozen watchfulness)

2. Diffuse attachments as manifested by indiscriminate sociability with relative failure to exhibit appropriate selective attachments (e.g., excessive familiarity with relative strangers or lack of selectivity in choice of attachment figures)

Criterion B. The disturbance in Criterion A is not accounted for solely by developmental delays (as in mental retardation) and is not a symptom of pervasive developmental disorder.

Criterion C. Pathogenic Care as evidenced by at least one of the following:

1. Persistent disregard of the child's basic emotional needs for comfort, stimulation, and affection

2. Persistent disregard of the child's basic physical needs

3. Repeated changes of primary caregiver that prevent formation of stable attachments (e.g., frequent changes in foster care)

Criterion D. There is a presumption that the care in Criterion $C$ is responsible for the disturbed behavior in Criterion $\mathrm{A}$. (e.g., the disturbances in Criterion A began following the pathogenic care in Criterion $\mathrm{C}$ ).

Specify type:

Inhibited type: If criterion Al predominates in the clinical presentation

Disinhibited type: If criterion A2 predominates in the clinical presentation

Note. From Diagnostic and Statistical Manual of Mental Disorders, Fourth Edition (p. 118), by the American Psychiatric Association, 1994, Washington, DC: Author. Copyright 1994 by the American Psychiatric Association. Adapted with permission.

\section{Appendix B}

\section{ICD-10 Criteria for Attachment Disorders}

\section{Reactive Attachment Disorder}

A. Onset before age of 5 years.

B. Strongly contradictory of ambivalent social responses that extend across social situations (but which may show variability from relationship-to-relationship).

C. Emotional disturbance as shown by misery, lack of emotional responsiveness, withdrawal reactions, aggressive responses to one's own or another's distress, and/or fearful hypervigilance.

D. Evidence of capacity for social reciprocity and responsiveness as shown by elements of normal social relatedness in interactions with appropriately responsive, non-deviant adults.

E. Does not meet the criteria for pervasive developmental disorders.

\section{Disinhibited Attachment Disorder}

A. Diffuse attachments as a persistent feature during the first five years of life (but not necessarily persisting into middle childhood). Diagnosis requires a relative failure to show selective social attachments manifested by:

i. A normal tendency to seek comfort from others when distressed.

ii. An abnor mal or relative lack of selectivity in the person from whom comfort is sought.

B. Poorly modulated social interactions with unfamiliar persons. Diagnosis requires at least one of the following: generally clinging behavior in infancy or attention seeking and indiscriminately friendly behavior in early or middle childhood.

C. Lack of situation-specificity in the aforementioned features. Diagnosis requires that the first two features are manifest across the range of social contexts experienced by the child.

Note. From the ICD-10 Classification of Mental and Behavioral Disorders: Clinical Descriptions and Diagnostic Guidelines (pp. $279-$ 282), by the World Health Organization, 1992, Geneva, Switzerland: Author. Copyright 1994 by the World Health Organization. Adapted with permission.
Received August 26, 1993

Revision received January 14, 1995

Accepted July 10, 1995 